Revista Iberoamericana, Vol. LXXV, Núm. 226, Enero-Marzo 2009, 55-70

\title{
TÁNTALO EN BUENOS AIRES. RELACIONES LITERARIAS Y BIOGRÁFICAS ENTRE PIÑERA Y BORGES
}

\author{
POR \\ Alfredo Alonso Estenoz \\ Luther College
}

Una de las etapas más importantes en la vida del escritor cubano Virgilio Piñera (1912-1979) es su estancia en Argentina, donde vivió por tres períodos entre 1946 y 1958. Allí, como se sabe, escribió parte significativa de su obra, estableció relaciones con varios círculos literarios, presidió el comitéde traducción de Ferdydurke, la novela del polaco Witold Gombrowicz, publicó cuentos, críticas y su novela La carne de René (1952), sirvió como corresponsal de la revista Ciclón y como agente literario de otros escritores cubanos, y escribió críticamente sobre Borges y sobre literatura argentina en general. Toda una vida dedicada a la literatura o a su causa (en esos términos de batalla solía referirse a su labor). De estas numerosas actividades, se hace siempre énfasis en la traducción de Ferdydurke y en la polémica con Borges y otros escritores incluidos en la vertiente de la literatura argentina del momento que Piñera caracterizó como "influida por las corrientes culturales europeas" (Espinosa, Virgilio 115). ${ }^{1}$

Mi propósito, al escribir sobre esos años, es mostrar cómo la interacción de Piñera con la literatura porteña del momento sirvió más que al simple propósito de la polémica estética, y cómo otros textos suyos reflejan un complejo mundo de concepciones sobre el arte que pueden explicar, de manera más completa, sus ideas sobre la literatura argentina y en especial sobre Borges. Me concentraré particularmente en su relación literaria y, en menor medida, biográfica con este escritor. Sus ideas sobre él y otros autores argentinos están presentes no sólo en el breve artículo "Nota sobre literatura argentina de hoy" y en los fragmentos publicados de su autobiografía, La vida tal cual, ${ }^{2}$ sino también en varios textos de ficción escritos durante aquella etapa. Esas ideas no tienen lugar en el vacío, no son el producto de un observador externo que, de paso por Buenos Aires, puede

1 A esta vertiente se oponía la de "proyección nacionalista”, que "defiende el folclor y el autoctonismo, teniendo como símbolo literario el Martín Fierro” (Virgilio 115).

2 No existe una publicación completa de esta autobiografía. Varias revistas han dado a conocer fragmentos y he tenido la oportunidad de ver un manuscrito, también incompleto. 
expresar sin compromiso ni reservas sus opiniones, sino que forman parte central de sus concepciones literarias. La estancia en Argentina parece haberlas estimulado y confirmado, pero hay que verlas como parte de una reflexión sobre la escritura y la función del escritor latinoamericano.

I

Las fechas de las diferentes estancias de Piñera en Buenos Aires fueron especificadas por él mismo en su autobiografía y pueden confirmarse en la correspondencia con su familia y con el crítico y editor cubano José Rodríguez Feo. Dice Piñera: "Mi primera permanencia en Buenos Aires duró de febrero de 1946 a diciembre de 1947; la segunda, de abril de 1950 a mayo de 1954; la tercera, de enero de 1955 a noviembre de 1958". ${ }^{3}$ Las razones de cada permanencia son diferentes: "En la primera fui becario de la Comisión Nacional de Cultura de Buenos Aires; en la segunda, empleado administrativo del Consulado de mi país; en la tercera, corresponsal de la revista Ciclón que dirigía José Rodríguez Feo. La economía de la primera etapa fue saneada; la de la segunda irrisoria; la de la tercera, desahogada” (La vida 32-33).

Los detalles de esos viajes y las condiciones económicas en que vivió Piñera han sido tratados por otros autores, ${ }^{4}$ por lo queno me detendré en este aspecto. Sólo reiteraré que, en el primer viaje, venía como becario de la Comisión Nacional de Cultura de Buenos Aires -una beca conseguida gracias a la gestión de un profesor suyo en la Universidad de La Habana- y que salir de Cuba representó para él distanciarse de un mundo familiar, cultural y vital que le resultaba un tanto asfixiante, aunque tampoco reconociera un cambio esencial. Como le escribe a su hermana:

Pero, con todo, y aunque formalmente, he experimentado un cambio. Te digo formalmente, porque estos cambios no cambian la condición humana de uno [...] Aclarado esto, sí puedo hablar de cambio: salí del paisaje habanero, del Andino, del Don Q, de las intriguitas, del hambre, de los harapos. No quiero decirte que lo que ahora vivo sea mejor (nadie sabe qué es mejor o peor), pero al menos experimenté una traslación. (citado en Virgilio 115-16)

El contacto principal de Piñera en Buenos Aires era Adolfo de Obieta, hijo de Macedonio Fernández. Había intercambiado correspondencia con él desde 1943 y enviado un poema para la revista Papeles de Buenos Aires, donde fue publicado. ${ }^{5}$ Fue Obieta quien le presentó a Gombrowicz y al parecer propició el encuentro

\footnotetext{
3 La fecha de su regreso fue en realidad septiembre.

4 Véase, al respecto, el libro de Anderson y el artículo de Espinosa.

5 “Poema para la poesía”, Papeles de Buenos Aires (1944): 12.
} 
con Borges. Estos dos escritores representaban dos visiones divergentes del hecho literario, una diferencia en la que Piñera se sitúa activamente desde el inicio, tomando partido por Gombrowicz, pero manteniendo una relación de respeto con Borges (y a veces hasta maniobrando a favor de éste). ${ }^{6}$

Las circunstancias en las que Piñera y Borges se conocieron son algo difusas si nos atenemos a las dos versiones del cubano y al recuento de Thomas Anderson; en todos los casos, el artículo "Nota sobre literatura argentina de hoy" aparece como significativo. Piñera, según Anderson, había leído dicho texto en la radio, y Borges, al oírlo, se lo pide (53). El cubano, por su parte, escribe (en un texto cuyo origen no he podido precisar pero que tiene el mismo tono de la autobiografía):

Mi primer encuentro con Borges fue en "lo" de Wally Zenner, que vive en la calle Maipú, a sólo cinco cuadras de Borges, que también vive en Maipú. Lo acompañaba la Egeria de turno [quien] me presentó por segunda vez a Borges. Por segunda vez digo, pues ya había sido presentado a él por la dueña de la casa. Y digo la Egeria me presentó, con una presentación especial, porque por esos días yo había publicado en la revista Anales de Buenos Aires un artículo titulado "Nota sobre literatura argentina de hoy”, en el que hacía un breve análisis de la obra borgiana. Al momento percibí que a Borges le importaba un pito ser tenido por una de las divinidades tutelares de Buenos Aires. (citado en Virgilio 112)

En un fragmento que definitivamente pertenece a su autobiografía, Piñera cuenta una versión ligeramente distinta, según la cual ya conocía a Borges cuando escribió el artículo:

Borges reaccionó rogándome que le cediera el ensayo para publicarlo en Anales de Buenos Aires - revista de la que es director; al mismo tiempo, me hizo saber que aceptaba lo del tantalismo en lo que a él se refería, y por último, a manera de confirmación y soberanía insertaba en dicho mismo número de Anales, y junto a mi Nota, uno de sus relatos más tantálicos - "Los inmortales”. (La vida 34) ${ }^{7}$

La primera versión parece ser la menos exacta, puesto que ya desde octubre de 1946 Borges había publicado a Piñera en Anales de Buenos Aires (número 10), por lo que es posible que se conocieran desde entonces. Se trata del breve cuento “En el insomnio”, más tarde incluido por aquel y por Adolfo Bioy Casares en su antología Cuentos breves y extraordinarios (1955). También hay que tener en cuenta que "Nota sobre literatura argentina de hoy” se publicó casi simultáneamente en

${ }_{6}$ En su correspondencia con José Rodríguez Feo, ya como corresponsal de Ciclón, Piñera le propone aplazar para el próximo número un texto de Gombrowicz, por considerar que incluirlo afectaría sus relaciones con Borges y otros escritores.

7 Este fue el título original del relato, después cambiado a "El inmortal”. 
la revista habanera Orígenes. ${ }^{8}$ De la segunda versión, al menos se tiene el dato concreto de que la nota y el cuento de Borges aparecieron en el mismo número de Anales, aunque no uno al lado del otro, como recuerda Piñera. ${ }^{9}$

Thomas Anderson narra de manera diferente el encuentro entre los dos escritores, aunque sin especificar sus fuentes:

Piñera's first significant contact with Borges took place at a perfect moment, that is, shortly after Piñera submitted his story "El muñeco" to a literary contest organized by Sur. The members of Sur, who correctly interpreted the story as a mockery of Juan Perón and Peronism, were understandably not willing to take the risk of publishing it. Borges, who was an anti-Peronist to the core, must have been impressed and delighted by the originality of Piñera's story, given that shortly after reading it, he extended two important invitations to the young Cuban author. First, he urged Piñera to submit an original short story to Los Anales, and second, he invited him to present a conference on Cuban literature at the Sociedad Argentina de Escritores, of which Borges was president. Piñera accepted both offers. (50)

Como puede verse, la relación entre ambos comenzó con una buena dosis de respeto mutuo y de visión crítica por parte de Piñera, quien no tardó en escribir sobre la literatura argentina, y en particular sobre Borges. Sin embargo, tales diferencias (que se expresaron en más de un texto y no siempre de forma ensayística, como en la "Nota") no parecen haber representado tensión alguna para la amistad; todo lo contrario: ésta se extendió hasta finales de los cincuenta, cuando Piñera regresó definitivamente a Cuba. No existen datos para saber si la comunicación entre ambos continuó después de 1958, pero lo que sí está claro es que Borges dio varias muestras de consideración hacia la obra de Piñera durante aquellos años: además de la inclusión de "En el insomnio" en Cuentos breves y extraordinarios, hay referencias, en la correspondencia de Piñera con Rodríguez Feo, a las reacciones de Borges a varios de sus cuentos, a los tés con éste y su madre, y a su compromiso de entregar dos textos a la revista Ciclón. ${ }^{10}$

En el recientemente publicado diario de Adolfo Bioy Casares sobre sus conversaciones y su amistad con Borges, el nombre de Piñera aparece en tres

8 “Nota sobre literatura argentina de hoy”. Orígenes 4/13 (1947): 40-45. Resulta difícil determinar en qué publicación apareció primero. El número de Orígenes pertenece al trimestre de primavera, mientras que el de Anales de Buenos Aires corresponde a febrero, lo cual sugiere que Piñera pudo haberlo entregado a ambas revistas casi al mismo tiempo.

9 Tampoco fue su última colaboración con la revista porteña: en el número doble 15-16, de mayo-junio de 1947, Borges le incluyó el cuento "El señor ministro".

${ }^{10}$ El segundo, "Nota de un mal lector”, se publicó en 1956. Piñera estaba entusiasmado con que Borges hubiera priorizado la publicación cubana por encima de Sur, puesto que ambas preparaban al mismo tiempo un número sobre José Ortega y Gasset. 
ocasiones. En la primera se refiere una visita que hiciera junto a Rodríguez Feo a la casa de Bioy Casares el 18 de junio de 1956; por el tono de la anotación de ese día, no exenta de homofobia, ${ }^{11}$ parece ser la primera vez que tal encuentro ocurría. Se habla de varios temas y al final Borges disiente de Piñera en cuanto a la importancia de Lovecraft , a quien éste había llamado “el Poe de esta época” (172). La segunda referencia, del 16 de mayo de 1958, está en boca de Bioy Casares, quien relata una conversación de Piñera con Wally Zenner, en la que este se mostró preocupado por la reacción que el público de Buenos Aires pudiera tener ante la palabra “tetas", usada en su obra de teatro La boda. Borges comenta: "Entonces el destino se burló de nuestro amigo Piñera”, a lo que Bioy responde: “A cualquiera que escribe le pueden pasar estas cosas” (440). Borges se extiende entonces sobre los autores, entre los que incluye al cubano, que creen que "si se aventuran por el disparate encontrarán una mina” y dicen que quizás crean en los clásicos más que ellos mismos: "Los imaginan perfectos. No saben que son chambones, como todo el mundo” (440). La última vez que Piñera aparece en el diario es el 7 de junio de ese mismo año. Borges comenta que no le gustó el relato de aquél "La gran escalera del palacio legislativo”, que le parece “mal escrito, no creíble”. Agrega: "Se ve que el autor no imaginó nada. Que va inventando de cualquier modo, al azar de las palabras” (451). Como puede verse, estas observaciones revelan diferencias estéticas, pero aclaran poco sobre la relación personal, que parece amistosa.

Las opiniones fundamentales de Piñera sobre Borges están contenidas en su mayoría en "Nota sobre literatura argentina de hoy” y en su autobiografía. En ésta, Piñera define a esa literatura como tantálica. ${ }^{12}$ Una frase de Macedonio Fernández,

\footnotetext{
11 “A la noche comen en casa Borges, Wilcock, Peyrou y dos maricas cubanos, de la revista Ciclón: Rodríguez Feo, el director, y Virgilio Piñera, el secretario de redacción [...]. Los dos tienen inconfundible voz y entonación de maricas. Si forman pareja, Piñera ha de sufrir por los éxitos y las infidelidades de Rodríguez Feo” (169-70). Esta insistencia en la condición sexual de ambos cubanos muestra, por otro lado, que vivían su identidad abiertamente.

12 La imagen de Tántalo usada por Piñera viene de la parte más conocida del mito: la de su castigo en el infierno de acuerdo con el relato de Ulises en el famoso episodio del descenso al Hades, relatado por Homero en la Odisea. Tántalo es castigado -por haber tentado a los dioses al ofrecerles la carne de su propio hijo para ver si eran capaz de distinguir la carne humana- a estar en medio de una huerta abundante de frutas y agua, pero siempre que se dispone a probarlas, se alejan de mano. En inglés, el mito dio origen al verbo "to tantalize”, que significa, de acuerdo con el Webster's Dictionary, “to tease or torment by presenting something to the view and exciting desire but continually frustrating the expectations by keeping it out of reach" (2338). Este es el sentido que tiene la palabra en el texto de Piñera. No existe acepción para “tantalizar” en el Diccionario de la Real Academia u otros diccionarios de español.
} 
de su relato "Tantalia" (1930), le sirve para explicar el sentido que le da a la palabra: "Mi consigna interior, mi tantalismo, era buscar las exquisitas condiciones máximas de sufrimiento sin tocar a la vida, procurando al contrario la vida más plena, la sensibilidad más viva y excitada para el padecer” (35). Piñera entiende la actitud descrita por Macedonio como la posibilidad de simular, mediante el juego literario y la explotación de las capacidades expresivas, algo semejante a la vida, pero donde lo vital está ausente, una especie de juego con los sentimientos más complejos de la experiencia humana, pero no la exploración y la representación de esa experiencia.

La palabra parece haber tenido un sentido particular para el escritor cubano, pues en un momento de su autobiografía, escrita años después, la aplica a sí mismo para describir un fenómeno semejante. Luego de contar cómo, en su infancia, descubrió su homosexualidad y su sensibilidad para el arte, refiere que, de adolescente, todavía continuaba satisfaciendo ambos aspectos con la masturbación y la recitación de textos de otros. Tales actividades actuaban como sustituciones del sexo y el arte reales: "Expresar los pensamientos ajenos y evadir todo contacto real con el sexo se había convertido para mí en una mecánica cotidiana, matizada por el tantalismo que ponía yo en todos mis actos, si no llegué a chocar con la imbecilidad fue debido a una especie de contra yo que analizaba mis actuaciones” (La vida 27). Luego dice que, para curarse de ese estado, lo que se propuso fue simple: escribir literatura y tener relaciones sexuales. Lo tantálico aparece en él, entonces, como la idea de no estar participando de la existencia verdadera, sino de encontrar sustituciones para ella, de compensar por una falta o una imposibilidad.

Aplicada de manera general, tal caracterización de los autores argentinos implicaba que poseían dominio del lenguaje, de las técnicas narrativas y una sólida formación literaria, pero eran incapaces de expresarse a sí mismos. Al preguntarse por las razones de ello, se responde que el mundo que los rodea,

por su propia informidad y riqueza, los asusta, les parece contradictoriamente pobre, sin llamadas ni respuestas; un mundo al que no sabrían cómo arrancar el primer bocado... Por esto los vemos amurallados en un orbe metafísico gratuito, pleno de categorías intelectuales, planes de evasión, aporías zenonísticas, mores geométricos y mónadas leibnizianas. (175)

Piñera extiende sus consideraciones al escritor latinoamericano en general y, más aún, a todo habitante del continente. Para él, la condición del ser latinoamericano es la segunda naturaleza que se crea antes de entender o cultivar la verdadera, para lo cual se recurre a modelos europeos. Aplicado al campo de la creación literaria, esta segunda naturaleza es la ornamentación, la preocupación más por "la búsqueda de un [sic] fórmula formal del mundo que por la búsqueda de una forma en sí” (176). 
Veía la realidad del continente y la de sus sujetos como lo suficientemente ricas para engendrar o estimular formas nuevas y autóctonas, pero esa fuerza original estaba empañada por la presencia de los modelos de la cultura europea y por la negativa de los autores latinoamericanos a explorar las posibilidades narrativas que su propia realidad les ofrecía.

El otro problema que ve es el ocultamiento. La pregunta frente a una obra literaria latinoamericana, argumenta, no es qué quiso decir el escritor sino qué quiso esconder, y propone la siguiente solución:

No basta ser brillante, poseer un gran poder combinatorio, saber multiplicar el adorno a extremos sobrehumanos, dominar el idioma o los idiomas: hay que partir al fondo último de la conciencia y asentarse en un realidad muy real, que procurándonos cifras, llaves, conclusiones y respuestas, va, también, a otorgárselos al lector, para no dejarlo en la insólita, extraña situación de un mundo dado gratuitamente, y en el que, repetimos, siempre se preguntará por lo que el autor dejó oculto. (176-77)

El escritor a quien más espacio le dedica es Borges, cuyos cuentos ve escritos en aras de la construcción misma y donde "el obligado resorte vital que la justificaría no aparece” (179). Lo llama "logógrafo redivivo", término utilizado para referirse a los escritores en prosa de la antigüedad griega. ${ }^{13}$ "Se querría sinceramente que detrás de esta frase, de todas las demás frases de sus obras completas, hubiese algo que no fuera, por cierto, la frase misma” (180). Al final del artículo afirma que Borges debía mostrar al lector aquello que deja oculto y que resulta, por los menos, tan valioso como lo que expresa: “ ¿No es lo que queda oculto aquello que debería aparecer como expreso? ¿Y por qué Borges no se aventura a entregar a sus lectores esos 'ocultos'?” (181). O sea, concede que hay una realidad escondida en los relatos del argentino que éste se ha empeñado en velar; lo que debía hacer era declararla y, con ese material, hacer su literatura. Si Borges se decidiera, concluye, llegaría a ser comparable a Kafka o a Proust.

El texto de Piñera no constituye, como decíamos, una crítica incidental: no surge aislado de su circunstancia personal ni de los debates sobre la literatura argentina que entonces sostenían los propios intelectuales de este país. Con relación al primer aspecto, puede notarse desde el principio la idea, clave en la poética de Piñera, de enfrentamiento con el conocimiento acumulado. Se resiste a que sea ese conocimiento de la cultura y la literatura occidentales lo que conforme la obra. Ello

${ }^{13}$ El término se aplica comúnmente a los historiadores anteriores a Herodoto (484?-425? A.N.E.). También se usaba para nombrar a los escritores de cuentos en prosa y a quienes redactaban los textos que los acusados leían en su defensa en las cortes. Véase Encyclopaedia Britannica, "Logographi” 919. 
puede verse en su concepción de la escritura. Según cuenta en su autobiografía, desde el comienzo de su carrera literaria (al llegar a La Habana en 1938, adonde había venido, procedente del centro del país, a estudiar la carrera de filosofía y letras), la escritura se le presenta más como un reto que como un placer:

Ya en La Habana empezó en forma mi eterno combate contra la escritura. Porque no se lucha por la escritura sino en su contra. Desconfiar de aquellos escritores que afirman encantarle [sic] la literatura; obtener esa alquimia de entrada en la corriente sanguínea de nuestro cuerpo, es el combate que todo escritor debe plantearse. Escribir simplemente es un oficio como otro cualquiera; en cambio, escribirse uno, he ahí el secreto (Virgilio 77). ${ }^{14}$

La idea de escribirse es un tema recurrente en varios textos de la época y posteriores. Aparece como alternativa a la literatura que, según el autor, están escribiendo los escritores argentinos, la cual rehuye esa inmersión en uno mismo y prefiere buscar los temas en la tradición europea o en el paisaje nacionalista. En su autobiografía, Piñera anota una variación de esta idea:

Yo encontré en Buenos Aires gente tan culta, tan informada y brillante como la de Europa. Hombres como Borges, Mallea, Macedonio Fernández, Martínez Estrada, Girondo, los dos Romero, Bioy Casares, Fattono, Devoto, Sábato y muchos más pueden ofrecerse sin duda alguna como típicos casos de hommes de lettres. Sin embargo de tantas excelencias todos ellos padecían de un mal común: ninguno lograba expresar realmente su propio ser. ¿Qué pasaba con todos esos hombres que con la cultura metida en un puño no podían expresarse? (La vida 34)

O sea, el conocimiento, la capacidad expresiva, el dominio de la escritura no resultan suficientes para él, quien ve la clave en la capacidad para encontrar en uno mismo el motivo de la creación. En "Nota sobre literatura argentina de hoy", la idea se plantea como solución al peligro de la ornamentación. Aunque la frase "al último fondo de la conciencia hay que partir y asentarse en una realidad muy real” puede resultar ambigua, lo que está proponiendo es que la literatura debe funcionar como medio de conocimiento, de interacción con la realidad, y que debe ofrecer soluciones a los conflictos cotidianos, una dimensión que ve ausente en la literatura argentina.

La relación de sospecha que Piñera establece con el mundo de la cultura es algo que venía ocupándolo desde mucho antes, desde su llegada a La Habana. También en su autobiografía relata sus primeros contactos con el arte y cómo descubrió que,

${ }^{14}$ El libro de Carlos Espinosa es una biografía de construida a partir de fragmentos autobiográficos, cartas, entrevistas y otros textos de y sobre Piñera. El origen de muchos de esos textos no aparece especificado, por lo que resulta difícil citar con exactitud la fuente. 
a la par de pobre y homosexual, era artista. Ocurrió un día en que "escuché a una prima mía muy gorda que apretando convulsivamente una copa en su mano cantaba el brindis de “Traviata'” (La vida 23). Su solución ante el placer estético experimentado consistió en “el bocado de la imitación”: se vistió con las ropas de su madre y cantó lo que recordaba de la famosa ópera (25). De modo que su concepción temprana del arte implica una impostura, pero esta posición (según la ve posteriormente) contiene un peligro: "Pero ¡ay!, cada nuevo ejercicio de imitación nos va alejando su rostro y terminamos pisoteados por sus horrendos cascos" (25).

En aquellos años Piñera se puso en contacto con "el terreno así dicho del arte”, lo cual hizo

con dos tipos de gente en extremo dudosas. Las primeras formaban fila en las aulas de la Facultad de Filosofía y Letras; las segundas eran muchachos inclinados a lo bello, sensibles y amantes de las bellas artes. Unas y otras eran homosexuales [...] Eran muchachos pálidos, nerviosos, que no "perdían” un concierto, que hablaban afectadamente y hacían versos. (29)

Se extiende en descripciones del ambiente universitario y señala que, puesto a escoger entre el "corazón anatómico y poético", tenía obviamente que optar por el segundo. Se presenta entonces una contradicción, tan recurrente en Piñera, entre lo vital y el universo de la alta cultura. Pero esta última es vista ante todo como un conocimiento asimilado superficialmente, como una pose. Escribe: "podrían revirarse los ojos, caer en éxtasis, suspirar, si leíamos un verso de Dante o de Keats; la vista de una lámina que mostrara un vaso sagrado del templo de Amón o el Rapto de Proserpina nos autorizaría a vernos trasmutados en el sacerdote o en la diosa” (La vida 30). Al mismo tiempo, dice que no cayó completamente en aquel mundo porque, además de no tener dinero para comprar antigüedades (una de las ocupaciones favoritas de los que llama "homosexuales de garçonniere”), tenía “una suerte de sexto sentido que me dejaba ver lo ridículo de todo aquello" (30).

En estos pasajes puede verse el mismo tipo de reserva que luego señalará con respecto al ambiente literario de Buenos Aires: la adopción de una pose cultural, la capacidad de adorar lo que llama "el Arte" y "lo Bello" como abstracciones. Demuestran, también, que las ideas expresadas en "Nota sobre literatura argentina de hoy" no se deben únicamente a la circunstancia de encontrarse en Buenos Aires como observador de la dinámica literaria de esa ciudad, sino que forman parte de sus concepciones centrales sobre la escritura. 
III

En la tercera parte de este artículo me detendré en otros textos de Piñera que contribuyen a demostrar la centralidad que las ideas expresadas en su "Nota" ocupaban en su obra. Para ello analizaré el cuento "Concilio y discurso", fechado en 1950 pero inédito hasta su inclusión en el libro póstumo Muecas para escribientes (1987). Pudo haberse escrito en Buenos Aires, pues en 1950 Piñera regresó a esa ciudad en abril. También haré referencia a las revistas paródicas Aurora y Victrola, por la relación que tienen con otros textos del autor cubano.

Afirmar que "Concilio y discurso" constituye una referencia directa al ambiente literario de Buenos Aires carece de base. Pero lo que me interesa destacar es cómo los términos de su crítica están presentes, de manera ficcionalizada, en este relato. Pueden verse en algunas observaciones del narrador, en estructuras verbales y en el tema general del texto.

Escrito en primera persona, “Concilio y discurso" refiere los acontecimientos que siguieron a la nominación del narrador como "cameraman de los Sucesos Mundiales del Papado" (360).${ }^{15}$ El cuento desarrolla una idea que a Piñera le resultaba obsesiva y que abordó en distintas ocasiones: la trivialización, tanto de la vida cotidiana como de los temas trascendentes. Empieza con una reflexión del narrador sobre la naturaleza de la eternidad: éste se encuentra en el Vaticano, la Ciudad Eterna, y va a conocer personalmente al Papa. La ubicación -el Vaticano como centro espiritual del mundo, al menos católico- sitúa al cuento en el terreno de lo trascendente, pero lo trivial empieza a minarlo todo. De hecho, la decisión del Papa de nombrar un nuevo cameraman se debió a su rechazo del primero por el solo hecho de haber sido nominado. El narrador comienza a hacer observaciones paradójicas, sobre las cuales se construye prácticamente todo el texto. "Como todo al parecer en esta vida, la eternidad es un ser que nace, se desarrolla y muere” (360). En este momento se produce una instancia que parece una parodia de Borges. Dice el narrador que, al subir las escaleras, se sintió preso entre el pasado, el presente y el futuro, y anota: "Entonces cantó un pájaro: el automático movimiento de mi mano, puesta sobre mi pecho, y el pensamiento que convirtió el gorjeo actual en otro idéntico durante el reinado de Augusto, invalidaron el pájaro del presente, y cayó fulminado de su alta rama. Lo había ejecutado el veneno de la eternidad” (360).

La frase resuena demasiado a aquel pasaje de "Sentirse en muerte", relato de Borges de 1928, publicado originalmente ese año en El idioma de los argentinos e incluido como parte del artículo "Historia de la eternidad", que da título al libro de 1936. Dice Borges:

15 Todas las citas provienen de los Cuentos completos. 
Tal vez cantaba un pájaro y sentí por él un cariño chico y de tamaño de pájaro [...] El fácil pensamiento Estoy en mil ochocientos tantos dejó de ser unas cuantas aproximativas palabras y se profundizó a realidad. Me sentí muerto, percibidor abstracto del mundo [...] No creí, no, haber remontado las presuntivas aguas del Tiempo; más bien me sospeché poseedor del sentido reticente o ausente de la inconcebible palabra eternidad. (1: 366)

Hay aquí temas recurrentes en el autor de Ficciones: la anulación del tiempo como resultado de la fusión del pasado, presente y futuro; el pájaro como símbolo de esa eternidad. Sobre esta última idea, Borges escribió en 1951 "El ruiseñor de Keats”, artículo recogido en Otras inquisiciones (1952). Allí destaca que el poeta romántico sintió su propia mortalidad cuando oyó "el eterno ruiseñor de Ovidio y de Shakespeare” y "cuya voz, ahora, es la que en campos de Israel, una antigua tarde, oyó Ruth la moabita” (2: 95). También utilizó frecuentemente a los animales como símbolos de una percepción distinta del tiempo y de la sucesión. Le interesaba si éstos eran eternos porque representaban a la especie y no a los individuos, noción que parece tomar de Schopenhauer, a quien cita en este artículo.

La otra noción que utiliza con respecto a la temporalidad de los animales es que éstos, por ignorar la muerte, son eternos, idea desarrollada en "El inmortal", relato que Piñera conocía a fondo por haberse publicado en el mismo número de Anales de Buenos Aires en el que apareció su "Nota sobre literatura argentina de hoy” ${ }^{16}$ En el texto de Piñera, la inversión del tema se produce al considerar esa simultaneidad como mortífera y, en última instancia, trivial. La conversación que sigue sobre la eternidad revela más esta última perspectiva. Al ser presentado al Papa, éste le pregunta: “¿Cómo se encuentra en la eternidad finita?”, a lo que el narrador responde: “Eternamente efímero” (361).

El oxímoron, figura retórica que combina dos términos opuestos, será una de las maneras favoritas de Piñera de parodiar los temas caros a la alta cultura. Si en Borges la coexistencia de contrarios busca reflejar la imposibilidad de reducir los conceptos a un sentido único, de mostrar el lado convencional y arbitrario de los símbolos, Piñera, que emplea el mismo proceso, persigue la ridiculización de todo debate trascendente. El cuento hace una referencia al acto mismo de debatir, forma clásica de existencia de las reuniones literarias. El Papa afirma que "polemizar vale tanto como no polemizar" e inmediatamente arroja una lista de acciones y categorías posibles que, a pesar de su diferencia y de sus registros diversos, se sitúan todas en el mismo plano de importancia, desde la manzana del Paraíso hasta la posibilidad

\footnotetext{
${ }^{16}$ En el fragmento manuscrito de la autobiografía que pude consultar (debo agradecerle a Yonny Ibáñez el habérmelo mostrado), Piñera se dispone a hacer un análisis de "El inmortal” y reproduce el primer párrafo. En ese momento, el texto salta a una página diferente y a otro tema.
} 
de abrir una lata de salchichas. Más tarde se produce otra conversación entre el Papa y el narrador, en la que aquel le confiesa que "participaba, a la vez, de la naturaleza del asesino y del asesinado" (362). Al parecer, los cardenales estaban planeando asesinarlo, pero el Papa tiene varias estrategias, como asesinarse a sí mismo o fingir que lo hace. Confiesa, además, que milita en dos grupos rivales, la Opefaf y la Opifaf: "si pertenece al mismo tiempo a dos organizaciones enemigas, acaba por anular el mortífero poder de ambas” (363).

El narrador continúa con algunas reflexiones sobre la naturaleza de la filosofía, opuesta a la sencillez de la vida cotidiana. "Después de todas las complicaciones, de las caras graves, de las hondas reflexiones, del alma universal, sobrenadaba por encima de todo esto la punzante sencillez del mundo"(364). Entonces el Papa lo invita a unirse a una bola de gente que se ha formado y que, por su naturaleza, comunica su movimiento a quien se le acerque. El narrador se sorprende participando en tal ondulación. Nuevamente, en este plano todo se une, porque la bola representa el "maelstrom de lo trivial", donde todos los niveles de la experiencia y del pensamiento se encuentran en el mismo plano. Al movimiento de la bola se suman después diez teólogos y diez desteólogos. "Teólogos y desteólogos se fundieron en un abrazo apretado, que adoptaba la forma de la bola [...] Ya no se sabía qué eran, en la bola, teólogo y desteólogo. Sin embargo -iy qué inquietante!-por efecto de dicha confusión se llegaba a colmos de armonía, a empíreos de melodía” (369).

De repente empieza una conversación sobre bicicletas, que se extiende por el salón y alcanza a todos los presentes. La bicicleta, en este contexto, representa el ejemplo máximo de trivialización, porque se ha pasado de la discusión teológica a las reflexiones más absurdas sobre ese medio de transporte. El pasaje también se refiere a la capacidad de los allí presentes para asimilarse a la masa, para parecerse a los otros cuando las circunstancias lo requieren. Por ello, el narrador se ve obligado, aunque no quiera, a participar en la conversación sobre las bicicletas. La bola dicta las más incongruentes conversaciones. El Papa entonces da su sermón principal, sobre las bicicletas, resaltando que lo importante es el contagioso movimiento de éstas. Al finalizar, decide consumar el asesinato, pero como él es víctima y victimario al mismo tiempo, el crimen nunca sucede. El narrador anota: "Me percaté de que sería imposible el asesinato. Para que lo hubiera, las partes tendrían que estar de acuerdo -sacrificio gustoso-, o las partes en desacuerdo -víctima propiciatoria-. ¿Mas qué podían acuerdo y desacuerdo frente al terrible impacto de lo trivial?” (375). Finalmente, el protagonista admite que lo único importante es un golpe de efecto, que todo su conocimiento y su esfuerzo por convertir la dispersión en metodología no valen nada. Su propio golpe de efecto, en ese momento, consiste en gritar a toda voz que tiene una bicicleta verde. Alguien le da una y todos se ponen a pedalear, con el Papa al frente. 
Sería exagerado, como decíamos anteriormente, creer que este cuento es una parodia directa de algunos círculos literarios de Buenos Aires. Pero a lo largo de él resuenan los términos de la diferencia de Piñera con Borges. La presencia de los teólogos y desteólogos es otro ejemplo, que remite al cuento del argentino "Los teólogos”, de El Aleph (1949). En éste, la oposición entre contrarios termina por anular la importancia de cada uno. En su lucha respectiva por destruir al otro, el teólogo que resulta triunfante se da cuenta de que él y su contrincante han sido las dos caras de la misma moneda: "Aureliano supo que para la insondable divinidad, él y Juan de Panonia (el ortodoxo y el hereje, el aborrecedor y el aborrecido, el acusador y la víctima) formaban una sola persona” (1: 556). La identificación de los contrarios aparece como una constante de la obra de Borges: está en "Tema del traidor y del héroe", "El jardín de senderos que se bifurcan” y "El fin”, de Ficciones (1944); y en "Historia del guerrero y la cautiva", "Biografía de Tadeo Isidoro Cruz (1829-1874)” y “Deutsches Requiem”, de El Aleph, por citar unos pocos. Su tratamiento coincide con su idea de las compensaciones, desarrollada en "El inmortal” y “La biblioteca de Babel”, donde no hay una sola teoría que no esté refutada o compensada por otra. Refiere también, en un nivel más de la experiencia y menos filosófico, a la posibilidad de convertirse en la cosa que se odia. Así como la naturaleza de víctima y victimario del Papa en el relato piñeriano, su pertenencia a dos organizaciones enemigas terminan por anular toda preponderancia. La diferencia entre ambos cuentos radica en que, en el de Borges, los temas que debaten los teólogos son trascendentes, aunque estén usados, como él mismo señalara, con fines literarios y no filosóficos, ${ }^{17}$ mientras que en Piñera sirven para acentuar la incongruencia entre lo cotidiano y el mundo de la alta cultura.

El cuento contiene también ecos de "Nota sobre literatura argentina de hoy". Ante el debate que tiene lugar en el Vaticano sobre la eternidad, el narrador opone la simpleza de las cosas que acontecen alrededor de todos, como en la cita anteriormente reproducida: "sobrenadaba por encima de todo esto la punzante sencillez del mundo" (364). En el artículo, Piñera había señalado que, a los escritores argentinos, la realidad que pasaba frente a sus ojos se les escapaba, fascinados como estaban con los temas trascendentes, ajenos, según él, a esa realidad americana.

"Concilio y discurso" parece tener relación con la novela El banalizador, que, según varios testimonios, Piñera escribió en Buenos Aires y aún permanece inédita. Son pocas las referencias a ella, como una entrevista fechada el 1 de febrero de 1948 que el autor dio al periódico cubano El Mundo al regresar de su primera estancia en Buenos Aires:

\footnotetext{
17 Ver, por ejemplo, el epílogo de Otras inquisiciones, donde Borges declara famosamente que observa en él una tendencia "a estimar las ideas religiosas o filosóficas por su valor estético y aun por lo que encierran de singular y de maravilloso" (2: 153).
} 
Escribió también una novela: El banalizador, cuya publicación prepara la editorial Argos. La tesis de la obra es que se precisa banalizar la cultura. Se trata de una novela polémica, estructurada sobre lo grotesco y lo absurdo. Se lanza desde ella un ataque a la cultura moderna, en el empeño de conseguir un equilibrio de fuerzas a base de la vida sin simulación, sencilla y banal.

-¿Regreso a lo natural y espontáneo?, acotamos.

-Simplemente una concepción armoniosa de la vida. Equilibro entre la cultura y el mundo bajo, el de los instintos. Ofensiva, en suma, contra la retórica y contra el estilo ornamental. (citado en Virgilio 114)

En otra referencia al texto, Gombrowicz le pregunta en una carta (sin fecha pero presumiblemente de 1947): “¿A quién le ha leído, Piñera, el capítulo del Papa?”, y este escribe en una nota al pie: “Capítulo de mi novela El banalizador (aún inédita)” (Poesía y crítica 248).

Otra instancia donde se perciben resonancias de los términos de la discusión de Piñera son las revistas paródicas Aurora y Victrola. La primera fue escrita en colaboración con Gombrowicz, aunque puede afirmarse que su redacción pertenece casi completamente a Piñera, debido al dominio limitado que, del español, tenía el escritor polaco. Pero es en la segunda publicación, redactada por él íntegramente, donde Piñera muestra toda su capacidad paródica.

El primer texto de Victrola constituye una versión caricaturesca de las ideas expuestas en "Nota sobre literatura argentina de hoy":

Mi tema es la altura. Sin altura me sofoco. Lo de abajo me repugna, el sótano me da mareos, el subterráneo me apaga, la catacumba me simplifica. Yo quiero ser complicado, difícil, yo quiero elevarme. Pero los tiempos son difíciles. Cada día que pasa se pierde un metro de altura. La cultura, señoras y señores, es un problema de altura. Alta cultura en la altura y siempre ganando altura. ${ }^{18}$

Cita los supuestos poemas de dos autores del momento, luego de afirmar que la cantidad de poetas con que cuenta la ciudad le parece abrumadora:

\section{ESTREMECIMIENTOS}

¡Ah... ¡Eh... ¡Oh...

¡Ah... ¡Ah... ¡Ah...

¡Oh, no, no!

¡Uf... Sssss. ¡Puah!

${ }^{18}$ Las citas de ambas publicaciones vienen de la página de Internet. 


\author{
FURIOSO ESPEJO \\ Pupila. Puf. ¡Ah, ah! \\ No, no, pupila. ¡Puah! \\ Pupila. Sí, sí. ¡Ah! \\ No, pupila. ¡Jáu, jáu!
}

Nuevamente, la parodia se produce por la oposición de contrarios y la naturaleza oximorónica de la estructura verbal. La onomatopeya recuerda uno de los textos que el narrador de "Concilio y discurso" propone como alternativa a uno de los cuentos leídos en la reunión literaria que precede al concilio. Porque este comienza con una tertulia en la que los participantes deben entrenar sus labios para la conversación. Uno de los presentes lee en voz alta un relato, que provoca una exaltada reacción, lo mismo de condena que de aprobación. Entonces, el hombre opta por decir: "Paf a paf. Para paf con paf”, texto que genera un entusiasmo ausente en su lectura anterior. “¡Qué bien! Nada aburrido, nada denso”, exclaman los presentes (364). Los poemas ficticios recuerdan también al haikú de Oliverio Girondo, titulado "Nihilismo”, que Piñera reproduce en “Nota”: "Nada de nada: es todo. Así te quiero, nada. ¡Del todo!... Para nada”. La presencia, una vez más, del oxímoron constituye el ejemplo máximo de la naturaleza puramente ornamental de las palabras, de la relegación del sentido en aras de la expresión.

\title{
IV
}

La estancia de Virgilio Piñera en Argentina representó un período de intensa actividad creativa, duranteel cual se consolidaron algunos de sus presupuestos estéticos. El escritor cubano mantuvo una relación crítica con respecto a los autores argentinos, aunque al mismo tiempo participó activamente en la vida literaria de Buenos Aires, particularmente en su tercera estancia, cuando fungió como corresponsal de la revista Ciclón. Parece haber encontrado allí la manifestación concreta del tipo de dinámica cultural a la cual se oponía: que el mundo de la llamada alta cultura, identificada con la tradición literaria y filosófica europea, interfiriera en la percepción de la realidad latinoamericana, y que fuera este mundo el que dictara los temas y la manera de acercarse a ellos. Ello puede verse no sólo en la posición que el autor cubano asume en su texto más explícito al respecto, "Nota sobre literatura argentina de hoy”, sino también en varios textos de ficción, de los que el relato "Concilio y discurso” es un ejemplo. ${ }^{19}$ Aunque resulta imposible limitarlo a una crítica del ambiente literario

\footnotetext{
${ }^{19}$ Otro ejemplo sería “La risa”, fechado en 1947 e inédito también hasta 1987. El personaje principal y narrador se angustia ante la imposibilidad de tener un razonamiento simple sobre cualquier tema, sin que intervenga todo lo que ha leído al respecto.
} 
porteño, este texto contiene las mismas preocupaciones que afloran en varios textos críticos y en su autobiografía, lo cual evidencia la centralidad que tales ideas ocupaban en la labor crítica y creadora de Piñera.

\section{BiBLIOGRAFÍA}

Anderson, Thomas. Everything in Its Place. The Life and Works of Virgilio Piñera. Lewisburg: Bucknell UP, 2006.

Bioy Casares, Adolfo. Borges. Buenos Aires: Ediciones Destino, 2006.

Borges, Jorge Luis. Obras completas. 4 vols. Buenos Aires: Emecé Editores, 1996.

“Nota de un mal lector”. Ciclón 2/1 (1956): 28.

Espinosa, Carlos. "El poder mágico de los bifes. La estancia argentina de Virgilio Piñera”. Cuardernos Hispanoamericanos 471 (1989): 72-88.

Virgilio Piñera en persona. Denver: Término, 2003.

“Logographi”. Encyclopaedia Britannica. Vol. XVI. Cambridge: Cambridge UP, 1911. 919.

Piñera, Virgilio. Cuentos completos. Madrid: Alfaguara, 1999.

"Nota sobre literatura argentina de hoy". Poesía y crítica. México: FCE, 1994. 175-81.

Poesía y crítica. México: FCE, 1994.

La vida tal cual. Unión 10 (1990): 22-35.

Webster's Third New International Dictionary of the English Language. Springfield:

G. \& C. Merriam Company, 1971. 